\title{
A Hybrid Learning Approach for Subjects on Software Development of Automation Systems, Combining PBL, Gamification and Virtual Reality
}

\author{
Dênis Leite ${ }^{1}$, Higor Santos ${ }^{1}$, Ariane Rodrigues ${ }^{1}$, Cléviton Monteiro ${ }^{2}$, Alexandre Maciel ${ }^{1}$ \\ ${ }^{1}$ University of Pernambuco - Pernambuco - BR \\ ${ }^{2}$ Rural Federal University of Pernambuco - Pernambuco - BR \\ denisleite@poli.br, \{higor.monteiro, ariane.rodrigues\}@upe.br, \\ cleviton.monteiro@ufrpe.br, alexandre.maciel@upe.br
}

\begin{abstract}
Despite the practices laboratories and simulations, the traditional teaching and learning process on automation engineering remains with little adherence to the professional reality. In this context, this research proposes a hybrid teaching and learning approach, based on real problems, with virtual reality features and gamification strategies. Its main objective is to enhance the alignment between theory and practice, playfully and engagingly mirrored in the industry's need. The approach was developed based on Design Science Research and evaluated in seven classes of an undergraduate subject from the perspective of students and industrial professionals. The results evidence the evolution of the approach over the time and its ability to connect theory and professional practice.
\end{abstract}

\section{Introduction}

Due to the COVID-19 pandemic, the ministries of education in several countries are working to enable the adoption of new learning resources, to ensure the continuity of education (WORLD BANK, 2020). Amidst this sudden migration from face-to-face to online, there is a legitimate concern regarding quality and effectiveness, but on the other hand, there is a belief that this process will result in new and beneficial hybrid models (WEF, 2020).

According to Silva and Gomes (2015), the traditional learning process is considered inadequate for professional training, since it contributes to a passive posture of students by focusing on content exposure. In contrast to these practices, hybrid learning improves the process by combining face-to-face education enriched with virtual activities carried out at a distance (TORI, 2009). Given that, it is expected that the effectiveness of the learning process of software development for industrial automation is enhanced, if an active learning approach, such as Problem Based Learning (PBL) (HMELO-SILVER, 2004), is adopted. And even more, if it's engaged by problem solving held over realistic scenarios and gamification strategies, to make the process more fun and engaging (FADEL et al., 2014).

Given this context, the problem investigated in this research was the following: How to build a more engaging, fun and effective learning approach for industrial automation software development? In order to address this problem, the main objective was to build a Hybrid teaching and Learning Approach for subjects on Software Development of Automation Systems (HyLA-SDAS). It was developed based on the rigor of the Design Science Research (DSR), with implementations, deployment and evaluation over seven classes of the specified subject, from 2016 to 2019. Since this project was developed before the COVID-19 pandemic, its outcomes supported the continuity of the focused subject on distance learning and is being taken as reference to the refactoring process of others. 
Previous studies that address these trends have already been widely published at the Brazilian Symposium on Informatics in Education (SBIE) in the last 5 years. However, these studies did not consider the combination of Hybrid Learning (Schiehl, 2017), PBL (Macedo et al. 2019), Gamification (Lopes et al. 2019; Palomino, 2019) and Virtual Reality (Santana et al. 2014; Ramos et al. 2017) in the same process.

\section{Methodology}

Considering the research problem for the educational context and the objective of building a technological artifact (learning approach), we choose to use DSR to guide the planning, execution and evaluation of this research. This choice was mainly due to its ability to support an iterative development process, enabling the team to continuously improve the approach.

In this context, DSR supports researchers and professionals to solve human and organizational problems by extending their capabilities by creating innovative artifacts (Hevner et al. 2004; Wieringa, 2010). Hevner et al. (2004) states that DSR artifacts are defined as constructs (vocabulary and symbols), models (abstractions and representations), methods (algorithms and practices) and instantiations (implemented systems or prototypes). He proposed a conceptual framework with the intention of understanding, executing and evaluating the research.

In the present research, the proposed artifact is a teaching and learning approach for subjects on software development of automation systems, supported by a Virtual Learning Environment (VLE) and a Professional 3D Virtual Reality Environment (PVRE) as technological resources, and PBL and gamification strategies as methodological basis. The environment where the research has been performed is an undergraduate subject on software development for industrial machines at the University of Pernambuco (UPE). Its curricular plan includes enabling students to design software for automation systems, as well as specify hardware and deal with troubleshooting. It is a 60 hour discipline.

Figure 1 presents details of the conceptual framework by Hevner et al. (2004), contextualized for our research. As can be seen, as a theoretical basis, the concepts of Industrial Automation (PARENTE, 2011), Virtual Learning Environment (TORI, 2009), Problem Based Learning (HMELO-SILVER, 2004) and Gamification (FADEL et al 2014) were taken into account. The artifact development was carried out over 4 years in two cycles. The first from 2016 to 2017 and the second from 2018 to 2019. Each of these cycles involved studying and understanding the challenges for defining interventions, followed by prototyping and evaluation, by applying the artifact in different classes of the subject.

At the end of each academic semester, students and researchers presented suggestions, complaints and recommendations. After that, the viable ones were implemented and released for the next classes. The evaluation of the approach was done using 2 instruments: 1) a semi-structured questionnaire ${ }^{1}$ based on the Kirkpatrick (1994) was used to assess the students' perception regarding the adherence between the proposed artifact and the reality of the profession, and 2) expert opinion from professional engineers from different industries that were invited to evaluate projects presented by the students.

The semi-structured questionnaire was composed of 21 closed questions and 2 open questions grouped in the following categories: "motivation", "user experience", "knowledge"

\footnotetext{
${ }^{1}$ Link for the folder containing the questionnaire and its responses: https://drive.google.com/drive/folders/1JnXXZIXVdQPuwAESup0160QX812ZjquQ?usp=sharing
} 
and "suggestions and criticism". The experts were experienced automation professionals that work in different industries. Their opinion was collected from free speech in order to avoid any bias. The results are described in Section 4.

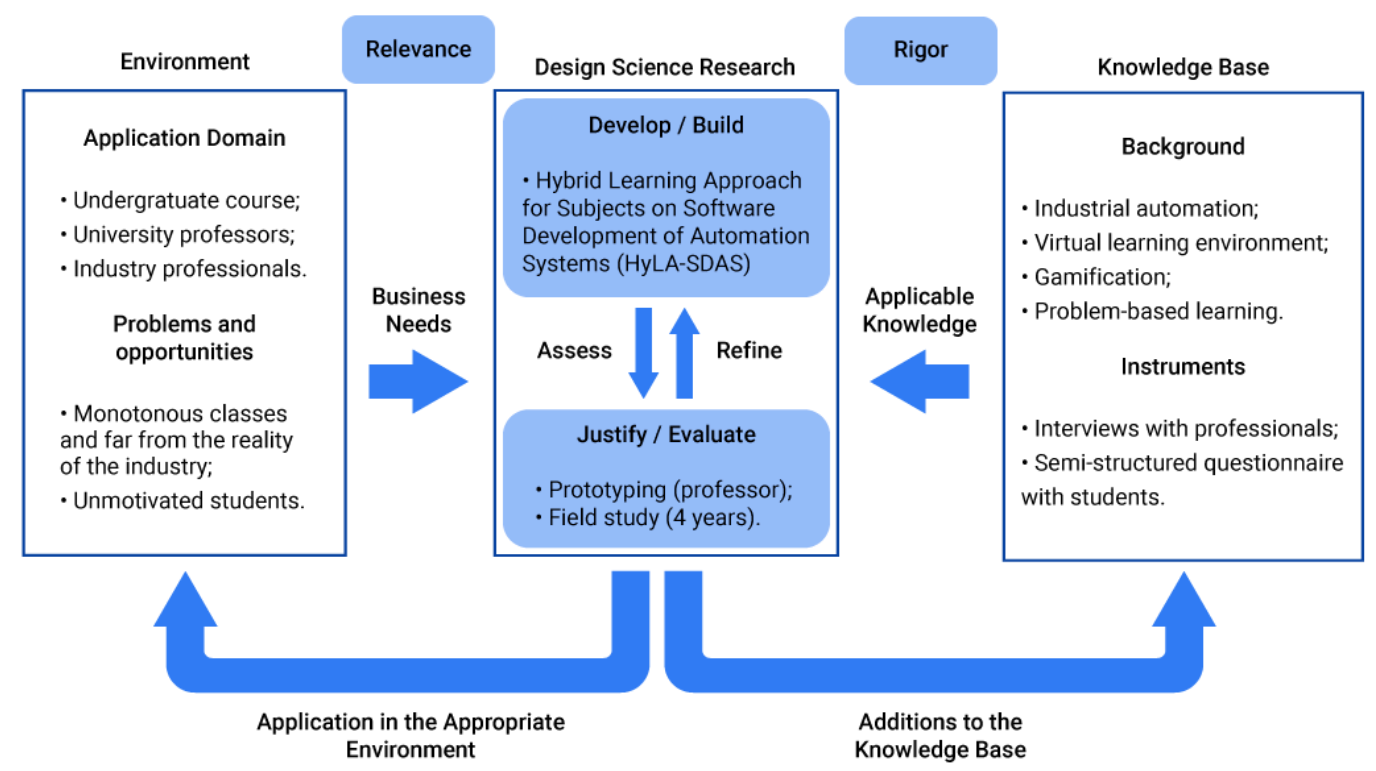

Figure 1. Framework of this research adapted from (Hevner et al., 2004)

\section{Development and Background}

This research was carried out by 5 professors and 2 students from the areas of Computing, Education and Industrial Automation of two Universities. It was also supported by two partners: one industrial automation solution provider and one software factory. Those enrolled at Computing and Education were responsible for specifying requirements regarding the design as an educational solution, both with regard to the teaching and learning process, the VLE and the PVRE, using PBL and gamification resources. Those from the industrial automation field were responsible for proposing problems and challenges based on the skills that should be fulfilled on the subject. And finally, the automation solution provider company and the software factory were responsible for developing and integrating the PVRE and the VLE that supported the HyLA-SDAS.

\subsection{Cycle 1 (2016-2017)}

The project began by mapping weaknesses arising from the unpreparedness of newly graduated professionals. We conducted interviews with managers from different factories using a semi-structured interview script. Based on the results, we verified that the professionals demonstrate solid theoretical background but lack practical experience. The problem arising from this is a latency until young professionals begin to contribute to improving the company's results, whether in project development or problem solving.

Given that, it was defined that the learning process of the subject should be able to prepare students, in practice, for real-life activities of design, development, implementation of automation systems and troubleshooting. To reach these goals, it was found that the approach should contemplate the adoption of an active learning approach, combined with gamification strategies to engage and motivate student participation, and a PVRE to promote professional activities very close to the reality.

The central approach defined was PBL since the aim is to train students to develop software for real-life situations and perform troubleshooting in automated machines. For 
Anais do XXXII Simpósio Brasileiro de Informática na Educação (SBIE 2021)

Hmelo-Silver (2004), problems are the starting point for learning and must require effort to be solved. In addition, it is important that students feel that the problem is relevant and worth solving. Thereby, we design gamification strategies based on a narrative that discusses the problems of an industry and its challenges.

Besides, characters were defined with specific roles and responsibilities: 1) the student is a newly hired trainee who needs to develop software to automate machines and perform troubleshooting; 2) the professor is the supervising engineer, whose responsibility is to present the projects and problems to be dealt with by the trainees, and 3) monitors were engineering assistants and consultants that supported the trainees in the activities with the supervision of the engineer. To motivate students, the projects and problems were designed so that the first and less complex ones would enable the development of knowledge, skills and competences that would be prerequisites for the next and more complex challenges.

The narrative and the interface between the students and the professor were the VLE, combining synchronous and asynchronous activities, while the practical activities were carried out in the PVRE, according to the guidelines presented in the VLE. The delivery of activities was carried out by sending videos to be evaluated by the professor.

Hybrid learning was adopted due to the possibility of promoting autonomy for students, allows for the adaptation of various learning methodologies (e.g., PBL and gamification) and increases student engagement (Tori, 2009). In this sense, we adopted a VLE and a PVRE to enable structuring content and execution of distance practices. Figure 2 highlights the technologies and interactions with students and professor.

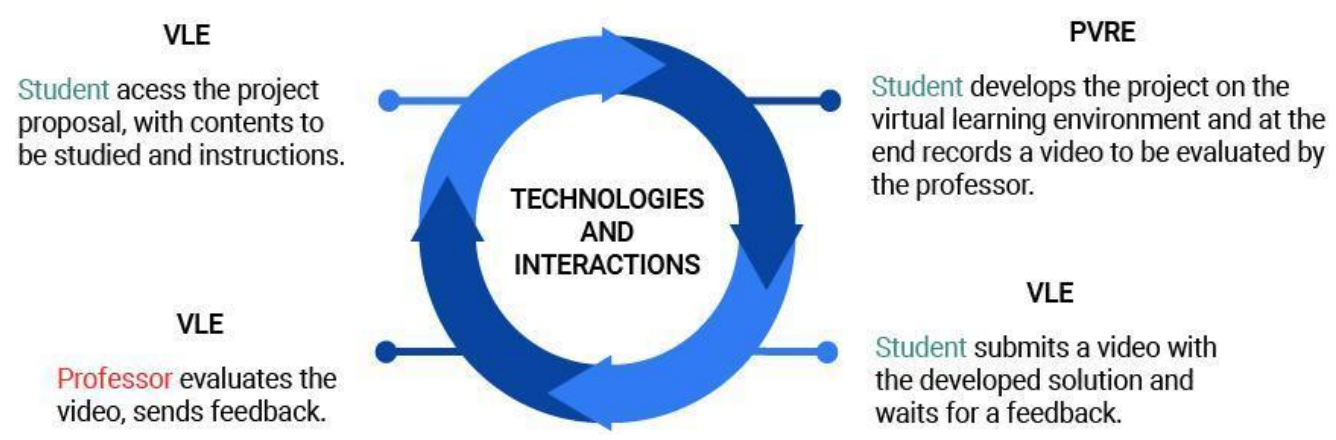

Figure 2. Technologies and interactions

The first version of the artifact (HyLA-SDAS) was prototyped using Moodle learning platform as the VLE and the MKSIM as PVRE. The choice of Moodle was due to its popularity, availability of supportive content, and the ease of implementation. The reasons for choosing MKSIM were its innovative features and realistic environments, as shown in Figure 3 , the fact it is in use at UPE and under continuous improvement, supported by entities FINEP, FACEPE, SEBRAE and CNPq with resources from economic subsidy to innovation.
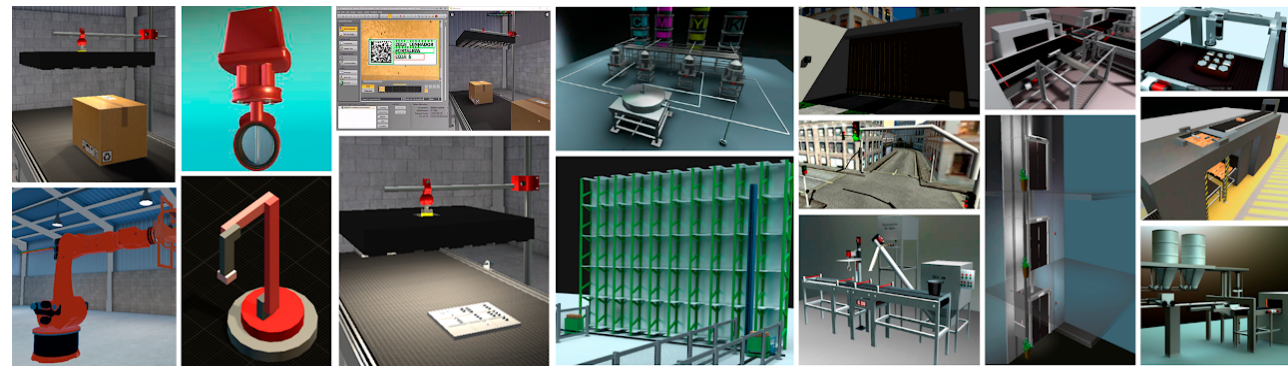

Figure 3: Environments where students develop and test software for automating machines. 
The teaching and learning process was planned to be carried out in weekly projects, where each project contemplated its context, instructions, guidelines, tips, download links for complementary materials and for necessary software. The presentation of the projects, as well as the contents, problems and gamification strategies were made available in the VLE, and the practical execution was carried out in the PVRE. Thus, the student moved between the VLE and the PVRE to understand the projects and problems and carry out the practices. Then each student had to upload a video explaining the solution to be evaluated by the professor.

The projects and problems should be designed within a week's time. In this way, every week students could work on the proposed project, asynchronously and upload the solutions through a video. Subsequently, in a synchronous and face-to-face moment, the professor conducted in-depth discussions as well as clarified students' doubts.

This first version of the HyLA-SDAS was applied in 3 academic semesters, 2016.2, 2017.1 and 2017.2. The classes were conducted by a professor skilled in industrial automation and with professional experience in the industry. At the end, students were asked to complete the surveys described in the Methodology section. Discussions of these assessments will be addressed in the following section.

\subsection{Results of Cycle 1 and Motivations for Cycle 2}

In the face of feedback received from students and from the professor of the subject, it was verified that it would be necessary to implement relevant changes in the approach and its supportive technologies. Table 1 shows feedback examples that represent the majority on the column at the left and requirements stated for Cycle 2 on column at the right.

Table 1

\begin{tabular}{|c|c|c|}
\hline Persona & Feedback & Requirement \\
\hline Student & $\begin{array}{l}\text { "Recording a video sometimes takes longer than } \\
\text { performing the activity." }\end{array}$ & \multirow{2}{*}{$\begin{array}{l}\text { 1. Automate the projects' validations to } \\
\text { dismiss deliveries through video } \\
\text { recordings. }\end{array}$} \\
\hline Professor & $\begin{array}{l}\text { "Evaluating all projects through watching videos } \\
\text { takes too long and requires daily activities to provide } \\
\text { early feedback to students." }\end{array}$ & \\
\hline Student & $\begin{array}{l}\text { "Without real-time feedback we get stuck and can't } \\
\text { solve issues when we are dedicated to the activities." }\end{array}$ & $\begin{array}{l}\text { 2. Provide automatic feedback to the } \\
\text { students when they try to deliver tasks. }\end{array}$ \\
\hline Professor & $\begin{array}{l}\text { "Although we recommend that the students work on } \\
\text { the project step-by-step, with guidance and tips, } \\
\text { some try to do it all at once and get complicated." }\end{array}$ & $\begin{array}{l}\text { 3. Split the project into steps guarantee } \\
\text { that a student will only access a new step } \\
\text { if the previous one was successfully } \\
\text { delivered. }\end{array}$ \\
\hline
\end{tabular}

\subsection{Cycle 2 (2018-2019)}

The main purpose of this second cycle was addressing the 3 requirements stated in Table 1. The projects are split into sequential tasks that can be accessed by the student only when the previous task is successfully delivered. This aims to keep the student focused on implementing only what is required at the task since it is the only way to move forward.

Besides, the contents were refactored: projects only presented the main goals and expected results, such as "machine $<\mathrm{x}>$ is to be automated to work $<$ this way $>$ due to $<$ these reasons $>$ ", while tasks had the detailed requirements, contents to be studied and tips, in a narrative such as "your job is to implement $<$ this $>$, in order to enable $<$ these operations $>$, the 
solution should meet <these requirements>, and to do so it is important to study <these topics $>$ ". Furthermore, an automatic task validation feature was implemented by means of a specialist system that gives students an automatic feedback that helps to interpret what is correct and what is wrong in the solution implemented by the student. Figure 5 illustrates an example of project-task structure with automatic validation and feedback.

As it can be observed, PVRE and the VLE were integrated, so that the PVRE is automatically set to the environment and conditions that are related to the active task or topic at the VLE, and when the student successfully delivers a task at the PVRE it notifies the VLE in order to enable the access to the next task.

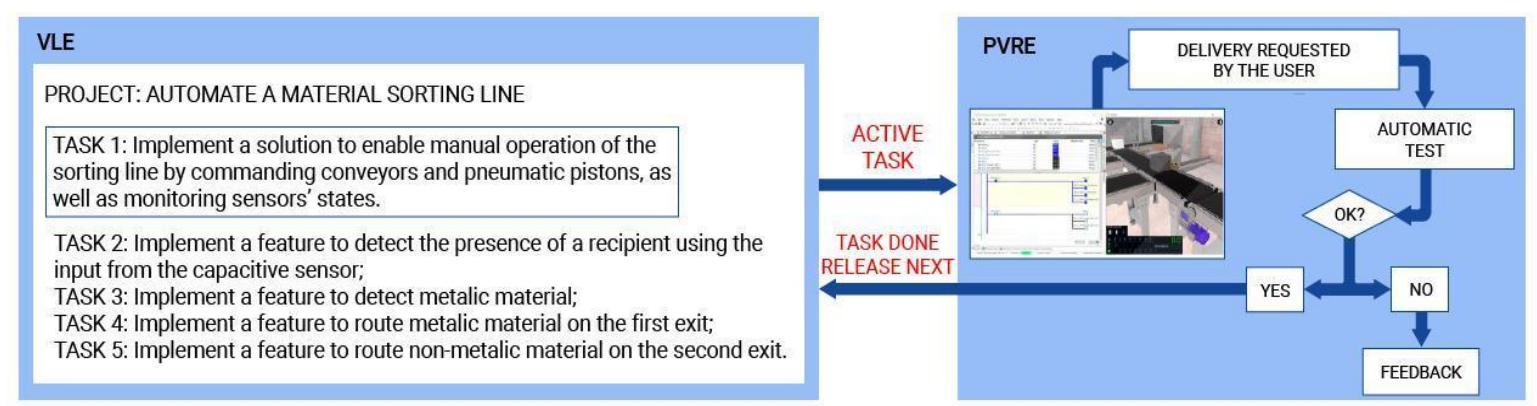

Figure 5. Example of project-task structure with integrated VLE \& PVRE

Since these interventions saved professors' and students' time, due to the fact that it was no longer necessary to produce (students) and evaluate (professors) videos, the content of the discipline was expanded. With that, the students started to develop the automation projects in 2 different automation platforms instead of one. This new version was applied in 4 classes, being 2018.1, 2018.2, 2019.1 and 2019.2.

\section{Results of evaluation of HyLA-SDAS over 4 years and discussion}

As indicated in section 2, HyLA-SDAS was evaluated regarding motivational aspects, usage experience and the knowledge acquired by students through applying a semi-structured questionnaire to students. In addition, was collected an expert opinion from experienced industrial engineers to identify their impressions about the results of learning with HyLA-SDAS in relation to how they learned themselves.

Regarding the questionnaire, questions associated with motivation, referred to the format of the subject, relevance of the contents to professional life and satisfaction when identifying the evolution of learning. Questions associated with experience, referred to immersion during the process of solving challenges in the PVRE, social interaction when collaborating in the distance learning process and entertainment. And finally, questions associated with knowledge referred to the students' perception of the adherence between the skills acquired during the course and the professional reality.

A total of 37 students answered the questionnaire: 14 from Cycle 1 and 23 from Cycle 2. The results brought evidence important points such as: $97 \%$ of the students agreed that the relation between what they are learning and the professional reality is clear; $91 \%$ agreed that they felt fulfilled and clearly understood what they learned as they delivered the tasks; $86 \%$ agreed that the contents in the tasks and projects are indeed relevant to their careers, that they clearly developed new skills as they advanced project-by-project, that they felt satisfied when their solutions met the requirements and the projects were completely done, and that they noticed their evolution at each new delivered task; $78 \%$ agreed that the way the discipline 
X Congresso Brasileiro de Informática na Educação (CBIE 2021)

Anais do XXXII Simpósio Brasileiro de Informática na Educação (SBIE 2021)

was planned and conducted was attractive their attention was properly captured; $81 \%$ agreed that having delivered the projects successfully enable them to re-use what they learned in other practical situations.

It was also possible to observe that $75 \%$ answered that they liked the way the subject was conducted and they had fun developing the projects; $85 \%$ answered that the fact that they were developing projects in a virtual reality environment motivated them to study more; $75 \%$ answered that the experience in the projects they developed enabled them to understand what skills and knowledge points they must improve; 91\% answered that using Whatsapp as communication tool was productive since answered to doubts were quickly given by professor, monitors and classmates; $97 \%$ said that they clearly noticed their own evolution at each new project done; $70 \%$ answered that they did work hard to have success in the subject; $75 \%$ agreed that the VLE combined to the PVRE were fundamental to follow the subject topics, learn the contents and develop the skills.

When comparing the results between cycles 1 and 2, important improvements were observed, such as: 1) the number of students that agreed that the way the discipline is planned and conducted catches is attractive and catches their attention was increased from $64 \%$ to $87 \%$; 2) the number of students that agreed that the contents are relevant to their careers rose from $79 \%$ to $91 \%$; and 3 ) the number of students that agreed that the projects motivate them to study more the concepts of the discipline was increased from $71 \%$ to $91 \%$. Therefore, the changes implemented on cycle 2 promoted a positive impact on the perception of the students in relation to the discipline and its relevance to their careers.

Naturally, some improvement necessities were identified such as: only $67 \%$ agreed that the practical activities' were adequately dimensioned regarding the time that was necessary to develop them; just $67 \%$ agreed that after working on troubleshooting of systems in the PVRE they felt prepared to handle real alike situations; only $56 \%$ of the students agreed that after developing projects and working on troubleshooting they felt like they could handle it in real situations, and that the feedbacks they received from the professor made them feel rewarded. In this regard, 3 points can be highlighted: 1) the necessity of continuously evaluate and adjust project proposals and tasks in order to keep them inside the time window that the students are expected to dedicate to the discipline; 2) the importance of introducing contents that clarify the adherence of what the students are doing in the PVRE and what they will be required to do in real working environment; and 3) the importance of providing feedback and reward them by different means.

The evaluation by expert opinion also brought new interesting findings. The majority of the experts highlighted the naturality and maturity with which the students could talk about their projects. In their words, they only reached that maturity level after some months or years of professional industrial experience. Furthermore, they said they were impressed with the capacity of the students to implement those solutions and solve the presented problems. They believe that if these students are hired as interns or trainees would be better prepared to face industrial challenges. The experts also mentioned that interns and trainees normally take a long time before they start contributing to delivering results because everything is new to them. However, those students that they just met in the presentations seemed to be very comfortable and used to the way the industry works, the timing, the equipment and so on. The expression they used was "they speak our language".

These findings lead to the conclusion that HyLA-SDAS was considered by professors, students and industrial professionals a better and more effective approach for the teaching 
and learning process of software development for automation systems, when compared to the traditional learning process which was the comparison baseline of both groups: students and professionals. Besides, the approach based on projects and problems, combined with gamification strategies and practical activities in a $3 \mathrm{D}$ environment that simulates the real professional environment proved to be effective on: 1) engaging the students, 2) evidencing the relevance of what was learned to the professional career, and 3) developing the skills that the subject is aimed to promote.

In this context, we highlighted that the main result of this research is a methodological-technological artifact, HyLA-SDAS, which is a teaching and learning approach based on 4 elements: 1) an active learning methodology (PBL), 2) gamification strategies, 3) a Virtual Learning Environment (VLE) and 4) a Professional Virtual Environment (PVRE). Furthermore, since it has been successfully applied in a real environment with evidence of its benefits in relation to the state-of-the-technique, it is also an innovation.

The development process guided by DSR, as described in section 3, presents detailed information about definitions, decisions, improvements and their reasons, as well as scientific and/or experimental background. So, it is expected to be useful as a guideline to other researchers that aim to work on the development of other solutions that combine innovative learning approaches and technologies.

The implementation of HyLA-SDAS in software development for automation systems subjects such as the one that was the development environment on this research can be done by using the exact same resources that were used in this research or by following the 8 steps as stated below to build another solution with other technological resources:

1. design a sequence of projects to be developed by the students, considering that each project is meant to develop specific knowledge and skills;

2. split the project in small tasks, so that by working in each task the student is incrementally implementing the project;

3. create a gamified narrative evolving a real professional context and the proposed projects;

4. adopt a VLE that supports integration with other systems to inform which task or topic is being accessed by the student and receive information to state the task as done;

5. adopt a PVRE that meets the following requirements:

5.1. is capable of simulating real professional situations in a $3 \mathrm{D}$ virtual reality environment;

5.2. supports the integration of automatic verification of the conformity between the student's solution and the requirement in the task;

5.3. supports the integration with the VLE to automatically set up the environment to the open task, and also send feedback about the successful conclusion of the task.

6. implement the course in the VLE;

7. configure the $3 \mathrm{D}$ VR environments in the PVRE;

8. implement the integrations between VLE and PVRE;

9. apply it in a real learning environment;

10. continuously evaluate it, adjust it and improve it.

The evaluation process and discussions highlight strengthens and weaknesses of HyLA-SDAS so that other researchers that aim to implement it, use it as a reference for new research or even develop better solutions and compare it, learn about the outcomes of the 
X Congresso Brasileiro de Informática na Educação (CBIE 2021)

Anais do XXXII Simpósio Brasileiro de Informática na Educação (SBIE 2021)

practical implementation.

One of the main takeaways of the authors themselves from this work was the benefits of using DSR to guide the research, because since the first moment the artifact was implemented, tested and evaluated over and over with the participation of the real users and in the real-world environment.

\section{Conclusion}

This work describes the development process, application and evaluation of an innovative Hybrid Learning Approach for Subjects on Software Development of Automation Systems (HyLA-SDAS) in a real environment. Synthetically, HyLA-SDAS is a teaching and learning approach based on an active learning methodology (PBL), gamification strategies, a Virtual Learning Environment (VLE), and a Professional Virtual Environment (PVRE). And it's been proven to be an innovation since it's been successfully applied in a real environment with evidence of its benefits in relation to the state-of-the-technique.

HyLA-SDAS was built to be a more engaging, fun and effective teaching and learning process for the referred subject. Therefore, in order to verify if those goals were met it was evaluated, over 4 years, in 7 subsequent classes of the same subject, by means of a semi-structured questionnaire applied to students and expert opinion. The evaluation with students brought evidence that the goals of turning the subject more fun, engaging and effective were met, while the expert opinion from experienced industrial professionals reinforced the effectiveness aspect of the approach on preparing the students to face the challenges in the real professional activities. And besides, HyLA-SDAS was applied, tested, evaluated and improved in a real environment, with real users from the first moment on, guided by DSR.

It is important to mention that the same professor conducted the 7 classes that were part of this research, therefore it's not possible to generalize the results of the application of HyLA-SDAS. However, the results show the capacity of the artifact to evolve and adapt, due to the used methodology DSR which includes: 1) experimenting from direct application in the real environment; 2) direct contact between researchers and end-users; and 3) continuous improvement. This process enabled a clear understanding of problems, the execution of improvements and the immediate observation of the results.

Other studies in progress include the application of machine learning techniques using data generated by the application of HyLA-SDAS, in order to early detect students at risk of failure, predict in which tasks students in a class should face difficulties in order to bring insights to the professor regarding what subjects focus on synchronous moments, and cluster tasks with information regarding unsuccessful delivery trials in order to identify what are the most common errors and how to improve the contents and better guide the students.

Future works should include the improvement of HyLA-SDAS as well as its application in other subjects, with other professors and in different institutions. This research was part of an innovation project leaded by the Automation Company, in partnership with the Software Factory and the University of Pernambuco, which has been financially supported by the institutions FINEP, FACEPE, SEBRAE and CNPq. The success of this initiative brings evidence of the importance of the integration between universities and the productive sector to generate value through innovation. 


\section{References}

Davis, F. (1989) "Perceived Usefulness, Perceived Ease of Use, and User Acceptance of Information Technology”. MIS Quarterly, v. 13, n. 3, p. 319-340.

Fadel, M. et al. (2014) “Gamificação na educação”. São Paulo: Pimenta Cultural, 300p.

Falcão et al. (2014) "Ferramenta de apoio ao ensino presencial utilizando gamificação e design de jogos”. XXV Simpósio Brasileiro de Informática na Educação SBIE.

Hevner, A. et al. (2004) "Design science in information systems Research". MIS Quarterly, v. 28 , n. 1 , p. $75-106$.

Hmelo-Silver, C. E. (2004) "Problem-Based Learning: What and How Do Students Learn?". Educational Psychology Review, Vol. 16, No. 3, September, 2004.

Johnson, L. et al. (2014). “Technology Outlook for Brazilian Universities: A Horizon Project Regional Report”. Austin, Texas: New Media Consortium.

Kirkpatrick, D. L. (1994) "Evaluating training programs: the four levels". San Francisco: Berrett-Koehler.

Lopes, Vinícius et al. (2019) Adaptive gamification strategies for education: a systematic literature review. Simpósio Brasileiro de Informática na Educação - SBIE.

Parente, F. (2011) “Automação Industrial - PLC - Programação e Instalação”. Editora LTC.

Palomino, Paula et al. (2019) Exploring content game elements to support gamification design in educational systems: narrative and storytelling. Simpósio Brasileiro de Informática na Educação - SBIE, p. 773, nov.

Ramos, David et al. (2017) Um modelo para Trilhas de Aprendizagem em um Ambiente Virtual de Aprendizagem. Simpósio Brasileiro de Informática na Educação - SBIE.

Santana et al. (2014) "Avaliando o Uso das Ferramentas Educacionais no Ambiente Virtual de Aprendizagem Moodle”. XXV Simpósio Brasileiro de Informática na Educação.

Schiehl, Edson Pedro; Gasparini, Isabela (2017) Modelos de Ensino Híbrido: Um Mapeamento Sistemático da Literatura. Simpósio Brasileiro de Informática na Educação SBIE, p. 1, out. 2017

Silva, A. e Gomes, A. (2015) "Conheça e utilize software educativo: avaliação e planejamento para a educação básica”. Recife: Pipa Comunicação, 216p.

Tori, R. (2009) "Cursos híbridos ou blended learning. Educação a distância: ao estado da arte”. São Paulo: Pearson Education do Brasil, p. 121-128.

WEF (2020) The COVID-19 pandemic has changed education forever. This is how. https://www.weforum.org/agenda/2020/04/coronavirus-education-global-covid19-online-d igital-learning/. Accessed in July 2020.

Wieringa, R. (2010) "Relevance and problem choice in design Science". Global Perspectives on Design Science Research, p. 61-76.

WORLD BANK (2020). How countries are using edtech (including online learning, radio, television, texting) to support access to remote learning during the COVID-19 pandemic. https://www.worldbank.org/en/topic/edutech/brief/how-countries-are-using-edtech-to-supp ort-remote-learning-during-the-covid-19-pandemic. Accessed in July 2020. 